\title{
Gravity field modelling and gravimetry
}

\author{
Jan Krynski \\ Institute of Geodesy and Cartography \\ Centre of Geodesy and Geodynamics \\ 27 Modzelewskiego St., 02-679 Warsaw, Poland \\ e-mail. jan.krynski@igik.edu.pl
}

Received. 17 March 2015 / Accepted: 25 April 2015

\begin{abstract}
The summary of research activities concerning gravity field modelling and gravimetric works performed in Poland in the period of 2011-2014 is presented. It contains the results of research on geoid modelling in Poland and other countries, evaluation of global geopotential models, determination of temporal variations of the gravity field with the use of data from satellite gravity space missions, absolute gravity surveys for the maintenance and modernization of the gravity control in Poland and overseas, metrological aspects in gravimetry, maintenance of gravimetric calibration baselines, and investigations of the nontidal gravity changes. The bibliography of the related works is given in references.
\end{abstract}

Keywords. gravity field, geoid, quasigeoid, absolute gravity, gravimetry, global geopotential model, height anomaly

\section{Introduction}

Substantial progress in gravity field modelling and gravimetry is observed in last decades. They are traditional areas of research activities in Poland. The extensive information on those activities has been presented in consecutive quadrennial Polish National Reports on Geodesy for IUGG and in the annual National Reports to the IAG Sub-commission for EUREF. In a period of 2011-2014, researchers from the following research centres. Centre of Geodesy and Geodynamics, Institute of Geodesy and Cartography in Warsaw (IGiK); Department of Geodesy and Geodetic Astronomy, Warsaw University of Technology (WUT); Department of Planetary Geodesy, Space Research Centre, Polish Academy of Sciences in Warsaw (SRC); Department of Surveying Engineering, University of Warmia and Mazury in Olsztyn (UWM); and the Institute of Geodesy and Geoinformatics, Wroclaw University of Environmental and Life Sciences (UPWr), Centre of Applied Geomatics, Military University of Technology in Warsaw (MUT) were involved in gravity field modelling and gravimetric works. Most of the results of their research were presented on international conferences; some were published in the 
international journals. In particular, a historical review of gravimetry for geodesy and geodynamics has been elaborated (Krynski, 2012b).

Application of the method of local quasigeoid modelling based on the geophysical technique of gravity data inversion using non-reduced surface gravity data and GNSS/ levelling height anomalies (GGI method) was investigated in UPWr and verified on tree test areas in Poland. An extensive research on evaluation of GOCE-based global geopotential models (GGMs) has been conducted by the team of IGiK. Terrestrial gravity data as well as GNSS/levelling data from the territory of Poland due to high quality are found suitable for accuracy evaluation of not only most recently developed geoid models but also of GGMs. In particular, an attempt was made to use absolute gravity data for the evaluation of GGMs. Also the use of GOCE-based GGMs in the process of geoid determination in Poland and in Sudan was investigated in IGiK. Some achievements in the field of geoid determination in the area of Poland in the last two decades were summarized and performance of new geoid model for Brunei was analysed by the researches from UWM and UPWr.

Temporal variations of gravity field were the subject of research in three research centres in Poland. Investigations conducted in IGiK concentrated on the estimate of geoid height variations in different regions of Europe and their modelling. Researches from SRC and UWM investigated the use of Wiener-Kolomogorov and ANS filters for filtering GRACE and analysed time series of equivalent water thickness in southern Poland.

Main activities in gravimetry were focused on the use of absolute gravity surveys for the maintenance of the national gravity control. The experience gained during the re-survey gravity control in Finland with the A10-020 gravimeter of IGiK were used in the projects on modernization of gravity control in Denmark, Norway, and Sweden and finally the establishment of new gravity control in Poland. Special attention was paid to metrological aspects of absolute gravimetry, in particular reliability and repeatability of gravity determination with the A10-020 gravimeter as well as total uncertainty budget for that gravimeter.

Very important component of research in gravimetry in Poland concerned the analysis of the absolute gravity measurements regularly performed with the A10-020 on the stations of the test network in Borowa Gora Geodetic-Geophysical Observatory (IGiK) and with the FG5-230 in the Astrogeodetic Observatory in Jozefoslaw (WUT). Absolute gravity determinations in the Geodynamic Laboratory in Ksiaz (SRC) were also analysed. Wavelet decomposition in the Earth's gravity field investigation was a subject of study by the joint team of MUT and SRC.

Some results of research on gravity field modelling and gravimetric works performed in Poland in a period of 2011-2014 are presented. 


\section{Geoid/quasigeoid modelling and study of the gravity field in Poland}

\subsection{Evaluation of GOCE-based GGMS}

Since the mid of 2010, global geopotential models (GGMs) based on GOCE mission data became available. They became the subject of the intensive study of the team of the Institute of Geodesy and Cartography, Warsaw. The area of Poland has been selected as a case study area of GGMs. It seems specifically suitable for the accuracy assessment of GOCE-based GGMs due to the availability of high-precision quasigeoid model (accuracy below $2 \mathrm{~cm}$ ) (e.g. Krynski, 2007) and homogeneously distributed highprecision GNSS/levelling data as well as accurate and dense terrestrial gravity data.

GOCE-derived GGMs were evaluated in terms of height anomalies and gravity anomalies over Poland with the use of the respective functionals calculated from the EGM08 geopotential model as well as height anomalies at 184 stations of high precision GPS/levelling control traverse. Analysis of first three releases of GOCE-based GGMs indicated an improvement of the consecutive releases of GOCE gravity field models. It also showed that their fit with the EGM08 in terms of height anomalies and gravity anomalies measured with a standard deviation is below $10 \mathrm{~cm}$, and $3 \mathrm{mGal}$, respectively (Godah and Krynski, 2011). Accuracy assessment of the $3^{\text {rd }}$ release of GOCE-based GGMs over the area of Poland using the EGM08 and GPS/levelling height anomalies was continued showing its high quality (Godah and Krynski, 2012). The investigation of $3^{\text {rd }}$ release GOCE-based GGMs which were developed using 12 months of effective GOCE data $\left(1^{\text {st }}\right.$ release was based on 2 months data, and $2^{\text {nd }}$ release was based on 8 months data), demonstrates that the differences between corresponding height anomalies along the control traverse exhibit a distinct periodic pattern with wavelength in the range of 183-188 km after the projection onto a parallel (Fig. 1). This pattern may indicate the suitability of using GPS/levelling control traverse for practical study of GOCE-based GGMs spatial resolution.

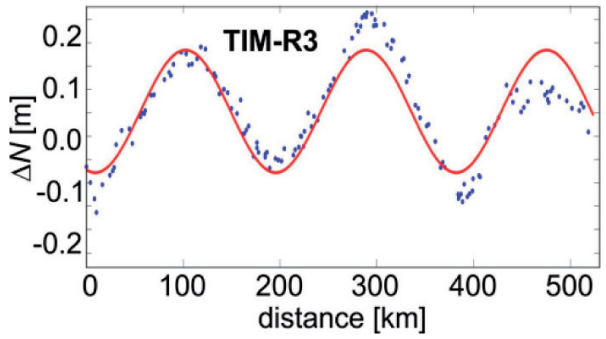

Fig. 1. Periodic pattern of the distribution of differences between the height anomalies from TIM-R3 and the corresponding ones from GPS/levelling at the control traverse

Further analysis concerning the accuracy evaluation of one GOCE-only GGM, four GOCE/GRACE satellite-only GGMs, and one GOCE/GRACE GGM combined with terrestrial gravity data showed an extremely good agreement of those models with the 
EGM08 (Table 1). It also demonstrated the potentiality of using the high-precision and high-resolution GPS/levelling control traverse for the evaluation of GGMs (Godah and Krynski, 2013a).

Table 1. Differences between height anomalies and gravity anomalies obtained from GOCE-based GGMs and the corresponding ones calculated from the EGM08 $\left(N_{\max }=200\right)$

\begin{tabular}{|l|c|c|c|c|c|c|c|c|}
\hline \multirow{2}{*}{ Model } & \multicolumn{4}{|c|}{$\zeta_{\mathrm{GOCE}}-\zeta_{\mathrm{EGM} 08}[\mathrm{~m}]$} & \multicolumn{4}{c|}{$\Delta g_{\mathrm{GOCE}}-\Delta g_{\mathrm{EGM} 08}[\mathrm{mGal}]$} \\
\cline { 2 - 10 } & $\min$ & $\max$ & $\operatorname{mean}$ & std dev. & $\min$ & $\max$ & mean & std dev. \\
\hline DIR-R3 & -0.281 & -0.006 & -0.159 & 0.051 & -3.433 & 4.215 & 0.076 & 1.381 \\
\hline TIM-R3 & -0.114 & 0.123 & 0.005 & 0.046 & -3.011 & 3.356 & 0.033 & 1.225 \\
\hline GOCO-03S & -0.100 & 0.109 & 0.000 & 0.044 & -2.897 & 3.057 & -0.004 & 1.184 \\
\hline DGM-1s & -0.441 & -0.111 & -0.300 & 0.066 & -3.836 & 5.143 & 0.036 & 1.794 \\
\hline EIGEN-06s & -0.384 & 0.017 & -0.159 & 0.064 & -5.994 & 4.813 & 0.098 & 1.780 \\
\hline EIGEN-06c & -0.299 & -0.034 & -0.162 & 0.042 & -3.504 & 3.212 & 0.017 & 1.041 \\
\hline
\end{tabular}

New developments in processing GOCE data resulted in new releases of GOCEbased GGMs. The fits of height anomalies obtained from $4^{\text {th }}$ release GOCE-based GGMs developed using 12 months of effective GOCE data, to GNSS/levelling data were investigated and compared with the respective ones of $3^{\text {rd }}$ release GOCE-based GGMs and the EGM08 (Table 2).

Table 2. Statistics of height anomalies differences between those obtained from GNSS/levelling data and the corresponding ones determined from the EGM08 (up to $\mathrm{d} / \mathrm{o} 2190$ ) as well as $3^{\text {rd }}$ release and $4^{\text {th }}$ release

GOCE-based GGMs (truncated at $200 \mathrm{~d} / \mathrm{o}$ ) extended with the EGM08 (from d/o 201 to 2190) [m]

\begin{tabular}{|c|c|c|c|c|c|c|}
\hline GNSS/levelling sites & Statistics & EGM08 & TIM-R3 & DIR-R3 & TIM-R4 & DIR-R4 \\
\hline \multirow{4}{*}{$\begin{array}{l}\text { POLREF } \\
315 \text { sites }\end{array}$} & $\min$ & 0.007 & -0.160 & -0.177 & -0.036 & -0.035 \\
\hline & $\max$ & 0.170 & 0.352 & 0.329 & 0.207 & 0.209 \\
\hline & mean & 0.100 & 0.089 & 0.090 & 0.093 & 0.095 \\
\hline & std dev. & 0.027 & 0.084 & 0.091 & 0.037 & 0.039 \\
\hline \multirow{4}{*}{$\begin{array}{l}\text { EUVN } \\
58 \text { sites }\end{array}$} & $\min$ & 0.019 & -0.071 & -0.126 & -0.007 & 0.025 \\
\hline & $\max$ & 0.173 & 0.256 & 0.278 & 0.168 & 0.191 \\
\hline & mean & 0.092 & 0.089 & 0.095 & 0.088 & 0.090 \\
\hline & std dev. & 0.028 & 0.079 & 0.085 & 0.036 & 0.039 \\
\hline \multirow{4}{*}{$\begin{array}{c}\text { Control traverse } \\
\left(1^{\text {st }}+2^{\text {nd }} \text { order }\right) \\
184 \text { sites }\end{array}$} & $\min$ & 0.027 & -0.172 & -0.212 & -0.025 & -0.023 \\
\hline & $\max$ & 0.126 & 0.284 & 0.282 & 0.122 & 0.136 \\
\hline & mean & 0.075 & 0.090 & 0.088 & 0.055 & 0.057 \\
\hline & std dev. & 0.022 & 0.101 & 0.105 & 0.030 & 0.036 \\
\hline \multirow{4}{*}{$\begin{array}{c}\text { Control traverse } \\
\left.\text { ( } 1^{\text {st }} \text { order }\right) \\
44 \text { sites }\end{array}$} & $\min$ & 0.043 & -0.126 & -0.103 & 0.006 & 0.020 \\
\hline & $\max$ & 0.126 & 0.269 & 0.248 & 0.122 & 0.136 \\
\hline & mean & 0.087 & 0.060 & 0.066 & 0.064 & 0.067 \\
\hline & std dev. & 0.019 & 0.112 & 0.107 & 0.027 & 0.032 \\
\hline
\end{tabular}


The fit of $4^{\text {th }}$ release GOCE-based GGMs truncated to d/o 200 and extended with the EGM08 coefficients to GNSS/levelling data ranges from 2.7 to $3.9 \mathrm{~cm}$ in terms of standard deviation of height anomalies differences. It exhibits clear improvement $(60-70 \%)$ with respect to the corresponding results obtained from the previous $3^{\text {rd }}$ release of GOCE-based GGMs. TIM-R4 GGM was found adequate for modelling the long-wavelength component (e.g. up to d/o 200) of the geoid over the area with high performance of the EGM08 such as the area of Poland. It has also been shown that $4^{\text {th }}$ release GOCE-based GGMs will considerably improve the determination of height anomalies in the areas where the EGM08 performs poorly, such as e.g. Africa, South America and South-East Asia. An accuracy of $2.1-3.3 \mathrm{~cm}$ of height anomalies obtained from $4^{\text {th }}$ release GOCE-based GGMs at maximum d/o 200 could be expected at any place on the Earth, except the poles and their adjacent areas that were not flown over by the GOCE satellite (Godah et al., 2014a).

The last, release 5 GOCE-based GGMs. DIR-R5 and TIM-R5, were also validated over the area of Poland. GNSS/levelling data were employed to evaluate height anomalies obtained from $5^{\text {th }}$ release GOCE-based GGMs. In addition, gravity anomalies from $5^{\text {th }}$ release GOCE-based GGMs were validated using the corresponding ones obtained from a high accuracy (i.e. beneath below $10 \mu \mathrm{Gal}$ ) absolute gravity data at almost 170 stations homogenously distributed over the area of Poland obtained with the absolute gravimeter A10-020 within the last two years (Fig. 2). The spectral enhancement method was used to overcome the spectral band inconsistency problem between the GGMs and the ground truth based data. The fit of the EGM08 and $5^{\text {th }}$ release GOCE-based GGMs in terms of gravity anomalies, measured with a standard deviation is $1.71 \mathrm{mGal}$, and 1.75-1.80 mGal, respectively (Godah et al., 2014c).
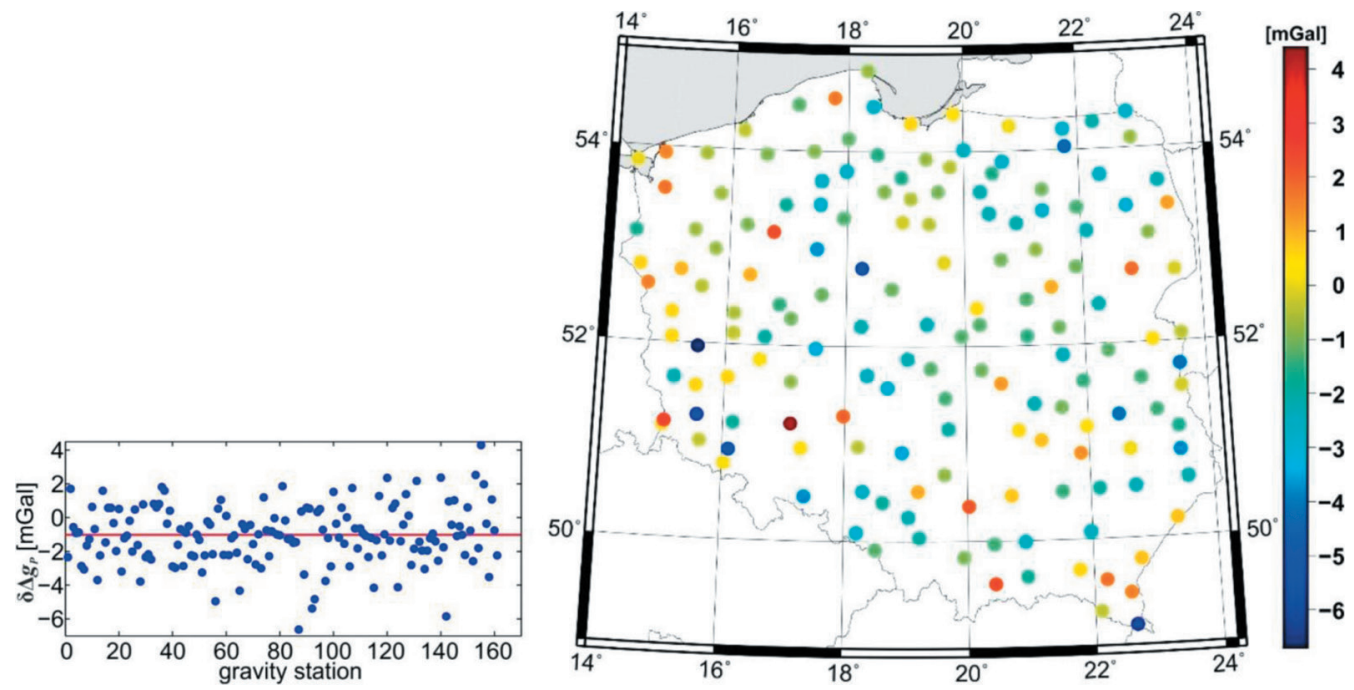

Fig. 2. GOCE-based GGM TIM-R5 vs. absolute gravity data 
The results of studies on GOCE-based GGMs conducted over the area of Poland have efficiently been applied for the assessment of the GOCE GGMs over the area of Sudan. In particular, the $3^{\text {rd }}$ release GOCE-based GGMs were compared in Sudan with the terrestrial gravity and GNSS/levelling data. The GOCE-derived free-air gravity anomalies and height were found consistent with the respective terrestrial ones within the range from 4.9 to $5.6 \mathrm{mGal}$, and $64 \mathrm{~cm}$, respectively (Godah and Krynski, 2013b).

The team of the Institute of Geodesy and Cartography, Warsaw, participated with the ballistic A10-020 gravimeter in re-survey of gravity control in Norway in 2011. The results of absolute gravity survey with the A10-020 in Norway in 2011 were used for the validation of GOCE-based GGMs in Southern Norway (Pettersen et al., 2012a, 2012b).

\subsection{Geoid modelling}

The quality of a gravimetric geoid model depends on the quality of the gravity data used as well as on the quality of the GGM applied for modelling low frequency component of the gravity field. $3^{\text {rd }}$ release GOCE-based GGMs, evaluated over Poland with the use of high-resolution and high accuracy terrestrial data, were applied to evaluate quality of terrestrial free-air gravity anomalies and height anomalies from GNSS/levelling data in Sudan. The GOCE-derived free-air gravity anomalies were compared with the respective ones from the terrestrial database using two different approaches. In the first approach high frequency gravity signals (e.g. 201 to $2190 \mathrm{~d}$ /o) were recovered with the use of the EGM08, and in the second approach a low pass filtering was implemented to remove those signals. It has been shown that the use of a low pass filtering provides better results for all investigated GOCE-based GGMs. The consistency of GOCE-derived free-air gravity anomalies with the respective terrestrial ones are within the range from 4.9 to $5.6 \mathrm{mGal}$. It was also shown that GOCE-based GGMs fit better in Sudan to terrestrial data than the EGM08. The results of the comparison of height anomalies from GOCE-based GGMs with the corresponding ones from GNSS/levelling data suggest the standard deviation of the vertical datum in Sudan at the level of $64 \mathrm{~cm}$. This estimate, however, might not be fully representative due to very limited number of GPS/levelling heights used and their inhomogeneous distribution (Godah and Krynski, 2013b).

The use of $3^{\text {rd }}$ release and $4^{\text {th }}$ release GOCE-based GGMs for modelling the gravimetric quasigeoid for Poland was investigated. Two highly accurate gravimetric quasigeoid models were developed over the area of Poland using high resolution Faye gravity anomalies with the use of remove-compute-restore strategy and least squares

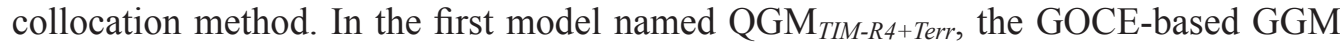
was used as a reference geopotential model, and in the second one named $\mathrm{QGM}_{E G M 08+T e r r}$ - the EGM08. The models were evaluated with GNSS/levelling data and their accuracy performance was assessed (Table 3).

The analysis of the accuracy of height anomalies obtained from the resulting gravimetric quasigeoid models indicates that for the area of Poland the gravimetric quasigeoid model based on the TIM-R4 GGM is slightly worse than the one based 
Table 3. Statistics of differences between height anomalies obtained from GNSS/levelling data and the corresponding ones obtained from combined gravimetric quasigeoid models $[\mathrm{m}]$

\begin{tabular}{|c|c|c|c|c|c|c|c|c|}
\hline \multirow{2}{*}{ Statistics } & \multicolumn{3}{|c|}{$\zeta_{\text {GNSS/levelling }}-\zeta_{\text {TIM-R4+Terr }}$} & \multicolumn{4}{c|}{$\zeta_{\text {GNSS/levelling }}-\zeta_{\text {EGM08+Terr }}$} \\
\cline { 2 - 9 } & POLREF & EUVN & \multicolumn{2}{|c|}{ Control traverse } & POLREF & EUVN & \multicolumn{2}{|c|}{ Control traverse } \\
\cline { 2 - 9 } & 315 sites & 58 sites & $\begin{array}{c}44 \text { sites } \\
\left(1^{\text {st }} \text { order }\right)\end{array}$ & $\begin{array}{c}184 \text { sites } \\
\left(1^{\text {st }}+2^{\text {nd }}\right. \\
\text { order })\end{array}$ & 315 sites & 58 sites & $\begin{array}{c}44 \text { sites } \\
\left(1^{\text {st }} \text { order }\right)\end{array}$ & $\begin{array}{c}184 \text { sites } \\
\left(1^{\text {st }}+2^{\text {nd }}\right. \\
\text { order })\end{array}$ \\
\hline Min & 0.023 & 0.057 & 0.065 & 0.040 & 0.020 & 0.047 & 0.069 & 0.037 \\
\hline Max & 0.215 & 0.224 & 0.152 & 0.153 & 0.231 & 0.215 & 0.146 & 0.153 \\
\hline Mean & 0.113 & 0.107 & 0.109 & 0.098 & 0.114 & 0.106 & 0.105 & 0.095 \\
\hline Std dev. & 0.028 & 0.033 & 0.021 & 0.024 & 0.029 & 0.031 & 0.019 & 0.021 \\
\hline
\end{tabular}

on the EGM08. It also reveals that the GOCE data cannot improve the modelling of the gravimetric quasigeoid for the areas with high performance of the EGM08, e.g. Poland, but such areas could be suitable to evaluate GOCE-based GGMs, in particular to estimate the accuracy of height anomalies obtained from those models. On the other hand, when 1-2 cm accuracy of geoid at d/o 200 obtained from GOCE mission is achieved, the GOCE-based GGMs might be considered in such areas as an independent tool to assess regional/local geoid/quasigeoid models as well as to detect outliers among GNSS/levelling data (Godah et al., 2014a).

Contribution of GOCE mission data to modelling regional gravimetric geoid in two areas with highly different terrestrial data availability, i.e. Poland and Sudan, was investigated. On the basis of the combination of $4^{\text {th }}$ release GOCE-based GGMs and local terrestrial gravity data, the gravimetric geoid models for the area of Poland as well as for the area of Sudan were developed using the least squares collocation method. The models were evaluated using GNSS/levelling data. The results for Poland and Sudan are given in Tables 4 and 5, respectively.

Table 4. Standard deviations of differences between height anomalies from gravimetric quasigeoid models in Poland developed using TIM-R4 or EGM08 with terrestrial gravity data and the corresponding ones obtained from GNSS/levelling data $[\mathrm{m}]$

\begin{tabular}{|c|c|c|}
\hline GNSS/levelling & TIM-R4 & EGM08 \\
\hline $\begin{array}{c}\text { POLREF } \\
315 \text { sites }\end{array}$ & 0.028 & 0.029 \\
\hline $\begin{array}{c}\text { EUVN } \\
58 \text { sites }\end{array}$ & 0.033 & 0.031 \\
\hline $\begin{array}{c}\text { Control traverse } \\
\left(1^{\text {st }}+2^{\text {nd }} \text { order }\right) \\
184 \text { sites }\end{array}$ & 0.024 & 0.021 \\
\hline $\begin{array}{c}\text { Control traverse } \\
\left(1^{\text {st }} \text { order }\right) \\
44 \text { sites }\end{array}$ & 0.021 & 0.019 \\
\hline
\end{tabular}


Table 5. Statistics of differences between geoid heights from gravimetric geoid model in Sudan and the corresponding ones obtained from GNSS/levelling data at 19 stations [m]

\begin{tabular}{|c|c|}
\hline Min & 0.096 \\
\hline Max & 2.066 \\
\hline Mean & 0.920 \\
\hline Std dev. & 0.644 \\
\hline
\end{tabular}

It has been shown that GOCE-based GGMs can substantially improve local gravimetric geoid models in the areas of lacking uniform terrestrial gravity data coverage, e.g. a sub-region of East Africa. GNSS/levelling data available in Sudan does not allow for the evaluation of the gravimetric geoid models at a few centimetre accuracy level; the use of GOCE-based GGMs is recommended for GNSS heighting in Sudan (Godah et al., 2014b).

The determination of accurate geoid model remains an important challenge for geodetic research in Sudan. For the area of Sudan a new gravimetric geoid model SUDGM2014 has been determined using TIM-R4 GOCE-based GGM, available terrestrial mean free-air gravity anomalies and the high-resolution Shuttle SRTM30 global digital terrain model. The computations of the SUD-GM2014 were performed using removecompute-restore procedure and the least squares collocation method. The residual terrain modelling reduction method was applied to estimate the topography effect on the geoid. The resulting gravimetric geoid model has been evaluated using geoid heights at $19 \mathrm{GNSS} /$ levelling points distributed over the country. The fit of the SUD-GM2014 to the available GNSS/levelling data in terms of the standard deviation of geoid heights differences is $64 \mathrm{~cm}$. Large mean of geoid heights differences (up to $90 \mathrm{~cm}$ ) are observed, which might imply serious problem within the vertical datum in Sudan. Therefore, re-establishment the levelling networks and uniform the vertical datum for the area of Sudan is essentially needed The use of GOCE-based GGMs for modelling the gravimetric geoid can play a significant role in the unification of the height system for the area of Sudan. Since GOCE-based GGMs provide geoid heights with the accuracy of 10-20 cm (Godah et al., 2014b), the SUD-GM2014 gravimetric geoid model or the geoid model computed from GOCE-based GGMs only is recommended as reference for GNSS heighting in Sudan (Godah and Krynski, 2014).

The review of some achievements of Adam Lyszkowicz in the field of geoid determination in the area of Poland using various data sets, and various methods, starting from 1992, has been presented by the author. Special attention has been paid on the evaluation of geoid models developed and the gravity field functionals calculated from the various global geopotential models. Also the need of fitting of computed geoid models to the national vertical reference system was stated. In conclusion the author stated that the present accuracy of gravimetric geoid/quasigeoid models in Poland is 1.4 $\mathrm{cm}$, and accuracy of the geoid computed from the EGM08 is $2.4 \mathrm{~cm}$. He also estimated accuracy of gravity anomalies and deflections of the vertical obtained from the EGM08 as equal to $2.5 \mathrm{mGal}$, and 0.6"-0.7", respectively (Lyszkowicz, 2012). 
A new gravimetric geoid model has been developed for Brunei with the use of terrestrial and airborne gravity data as well as altimetry data. The computation of the model was performed using the least squares collocation method and remove-computerestore procedure with the EGM08 global geopotential model. The estimated accuracy of the gravimetric geoid for the territory of Brunei is at the level of $0.3 \mathrm{~m}$. The geoid model developed shows poor quality of the existing GPS/levelling data in Brunei (Table 6) that indicates poor quality of local vertical datum (Lyszkowicz et al., 2014).

Table 6. Statistics of differences between geoid heights from gravimetric geoid model in Brunei and the corresponding ones obtained from GNSS/levelling data at 86 stations [m]

\begin{tabular}{|c|r|}
\hline Min & -43.80 \\
\hline Max & -36.94 \\
\hline Mean & -40.41 \\
\hline Std dev. & 1.58 \\
\hline
\end{tabular}

The GGImethod relies on developing a local model of disturbing potential (anomalous potential) $T$ in the outer space. The basic input data used in the calculations are. GNSS/ levelling height anomalies and non-reduced gravity data (gravity disturbances or freeair gravity anomalies referred to the terrain surface). The calculation is performed in four steps. In the first one that includes preliminary calculations, the GNSS/levelling height anomalies are converted using the Bruns' theorem to disturbing potential. Next, the local model of disturbing potential in external space is developed. Important elements of this model are discrete density distribution models of topographic masses and disturbing masses occurring between the geoid and the level of compensation. Once the model parameters are determined, disturbing potential is calculated in the new points on terrain surface which finally is converted to a height anomaly using again the Bruns' theorem.

Three examples of detailed local quasigeoid models calculated for three test areas of different size in Poland $\left(3900 \mathrm{~km}^{2}, 23000 \mathrm{~km}^{2}, 117000 \mathrm{~km}^{2}\right)$ and of different density of the gravity data coverage demonstrated the capacity of the method. For each test area three quasigeoid models were calculated. one without using a GGM, and the others with the use of the EGM96 and the EGM08, respectively. The results obtained indicate that the method is suitable for developing high accuracy local quasigeoid models (the accuracy obtained was at the level of accuracy of GNSS/levelling test data) (Trojanowicz, 2012a).

One of the main problems occurring in the application of the GGI method is to determine the density model weighting matrix that controls the inversion process. The results of test calculations provide the optimum range of constant coefficients that allow defining the model weighting matrix. The optimum values of coefficients have been designated for the different sizes of zones of constant density and for the approaches. without using a GGM, and with the use of the EGM96 and the EGM08 (Trojanowicz, 2012b). 


\subsection{Temporal variations of the gravity field from GRACE data}

Time variations of the gravity field obtained from the series of geopotential models developed from GRACE (Gravity Recovery and Climate Experiment) data can be interpreted in terms of geoid heights and mass time variations with unprecedented temporal resolution. The series of filtered monthly solutions of geopotential models developed from GRACE data and GLDAS (Global Land Data Assimilation System) hydrological models were used in the analysis. Variations of hydrology and geoid heights at the continental part of Europe and selected 14 subareas (Fig. 3) were estimated with a spatial resolution of $0.5^{\circ} \times 0.5^{\circ}$ for the period of August $2002-$ June 2010 .

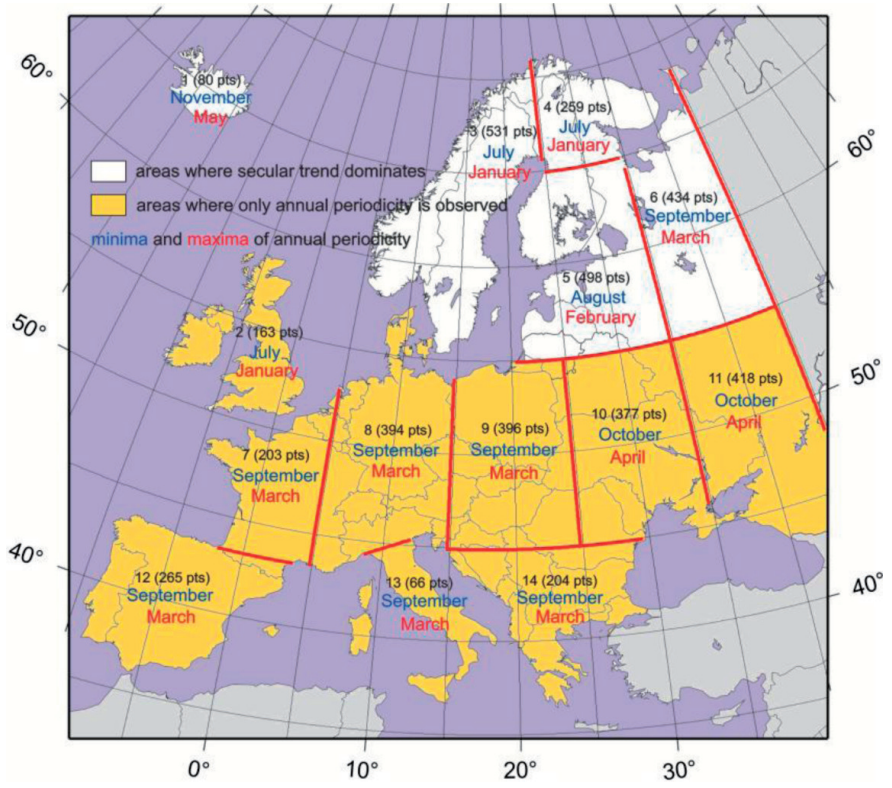

Fig. 3. The subareas of Europe with the number of points used to determine the average representative for each subarea (in brackets) as well as a trend and annual periodicity of equivalent water height variations (indicated months where minima and maxima occur)

Variations in mass distribution obtained from geopotential models were compared with the respective results obtained from hydrological data (Fig. 4).
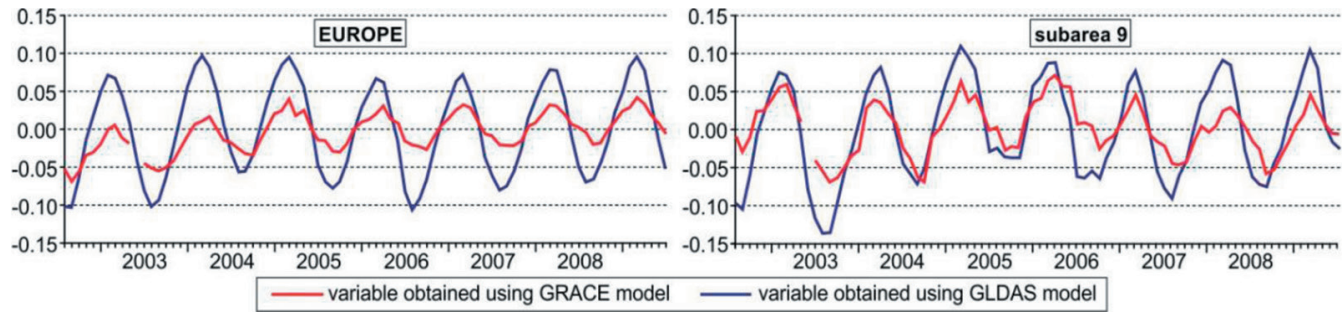

Fig. 4. Equivalent water heights variation obtained using GRACE and GLDAS models [m] 
Annual periodicity of hydrology and geoid height variations with minima in September and maxima in March is observed for the area of Europe. The linear trend is also present in the signal. It dominates the signal in Northern Europe (Norway, Sweden, Finland) where a secular trend due to Post Glacial Rebound is observed. In the subareas of Central Europe only an annual periodicity appears. Results obtained using GRACE data show high correlation with the results calculated using GLDAS hydrological models (Krynski et al., 2014a).

It has been shown that the temporal variations of the gravity field over Europe obtained from GRACE data in terms of the geoid height can efficiently be modelled. Models of geoid height changes consisting of the seasonal term with the period of 12 months, and a trend in the form of $2^{\text {nd }}$ order polynomial (trend and seasonal variations) were developed for the area of Europe and for 14 subareas. Optimum model for Europe and the subarea 9 (Fig. 3) against the observed variation of geoid height is presented in Figure 5. To verify those models values of geoid height changes calculated using GRACE data over the period of July 2010 - October 2010 were compared with the respective once based on the models developed.

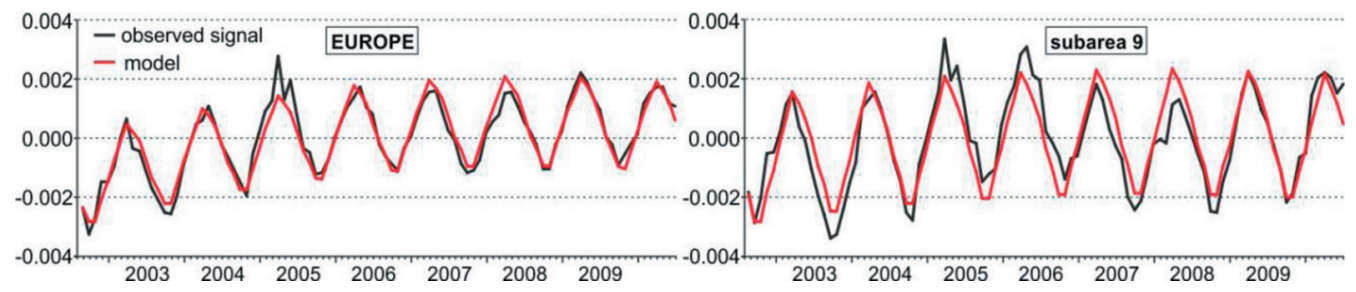

Fig. 5. Optimum model against the observed variation of geoid height [m]

Estimated averaged variations of geoid heights in the period of $2002-2010$ in the subarea covering Poland are within $7 \mathrm{~mm}$. In reality variations larger than $1 \mathrm{~cm}$ should be expected (Kloch-Glowka et al., 2012).

It was indicated that the concept of static geoid as a reference surface in precise heighting, with the use of contemporary global positioning techniques becomes outdated. Thus there is a growing need for kinematic models of the gravimetric geoid. It would require the continuation of the GRACE-type space missions (Krynski et al., 2012).

Models of the geoid height variations developed for Europe and its 14 subareas on the basis of GRACE data from the period of August 2002 - June 2010 were used to predict the geoid height variations for the next four months, i.e. July - October 2010. The predicted values were then compared with the respective ones obtained from the GRACE data. For Europe the correlation coefficient equals to 0.93 (Krynski et al., 2012, 2014a).

The phenomenon of flooding with the use of GRACE data was investigated. Equivalent water thickness (EWT) was determined using interpolation in places in southern Poland where flooding occurred in 2010. EWT time series were analysed and the results were verified with WGHM and NOAA hydrological models showing good mutual agreement. It has been shown that GRACE data can be used for testing the 
feasibility of predicting flood events in Poland. The preliminary tests performed using geological, forestry cover and soil type maps indicated the need for the extension of the analysis of EWT by taking into account issues related to meteorology, geology and soil science. The possibility of using GRACE data to implement the tasks arising from Directive 2007/60/EC of the European Parliament and of the Council on the assessment and management of flood risk was demonstrated (Birylo and Nastula, 2013a).

The research on the use of two isotropic filters. Gaussian, and CNES/GRGS, as well as two anisotropic filters. Wiener-Kolomogorov, and ANS for filtering GRACE data was conducted. Correlation, amplitude ratio, signal modification, and EWT maps were investigated. Best results in terms of correlation and amplitude ratio were obtained using ANS filter, while in terms of signal modification - with Gaussian filter (Birylo and Nastula, 2013b).

\section{Absolute gravity surveys}

\subsection{Absolute gravity surveys for the maintenance of national gravity control in Poland}

The use of portable ballistic gravimeter A10-020 for modernization of the Polish Gravity Control was investigated (Dykowski et al., 2012a). A set of recommendations and procedures have been developed. They were implemented during the establishment of new gravity control in Poland in 2012-2014 (Krynski and Dykowski, 2014b).

Research on modern vertical gravity reference systems (Krynski, 2012a, 2012b) and on the vertical gravity gradient determination for the needs of contemporary absolute gravity measurements (Dykowski, 2012a) was conducted at IGiK. In particular the structure of contemporary gravity control, the role of absolute gravity determinations, survey strategy and metrological problems were widely discussed. The results of the research as well as the experience gained during re-survey of gravity control in Finland with the A10-020 gravimeter were substantial in the project and the practical survey of new gravity control in Poland (Barlik et al., 2011b).

\subsection{Absolute gravity surveys for the maintenance of national gravity control in Denmark, Norway, Finland, and Sweden}

In the framework of the scientific cooperation between the Institute of Geodesy and Cartography, Warsaw, and the Finnish Geodetic Institute, 51 field sites of the Finnish gravity network (FOGN) were surveyed with the A10-020 gravimeter of the IGiK in 2009 and 2010 (Krynski, 2011; Krynski and Rogowski, 2011). First results of gravity change in Finland 1962-2010 from the comparison of legacy relative measurements with new measurements made with the A10-020 were obtained (Mäkinen et al., 2011).

Similar scientific cooperation concerning re-survey of national gravity control was later established between the Institute of Geodesy and Cartography, Warsaw, and the 
respective institutions in Denmark (National Space Institute, Technical University of Denmark, Copenhagen), Norway (Norwegian Mapping Authority, Oslo), and Sweden (Lantmäteriet, Geodesy Department, Gävle). The consecutive survey campaigns with the A10-020 gravimeter were conducted in Denmark in 2011, Norway in 2011 and in Sweden in 2011-2013 (Fig. 6) (Krynski and Rogowski, 2012; 2013; 2014).
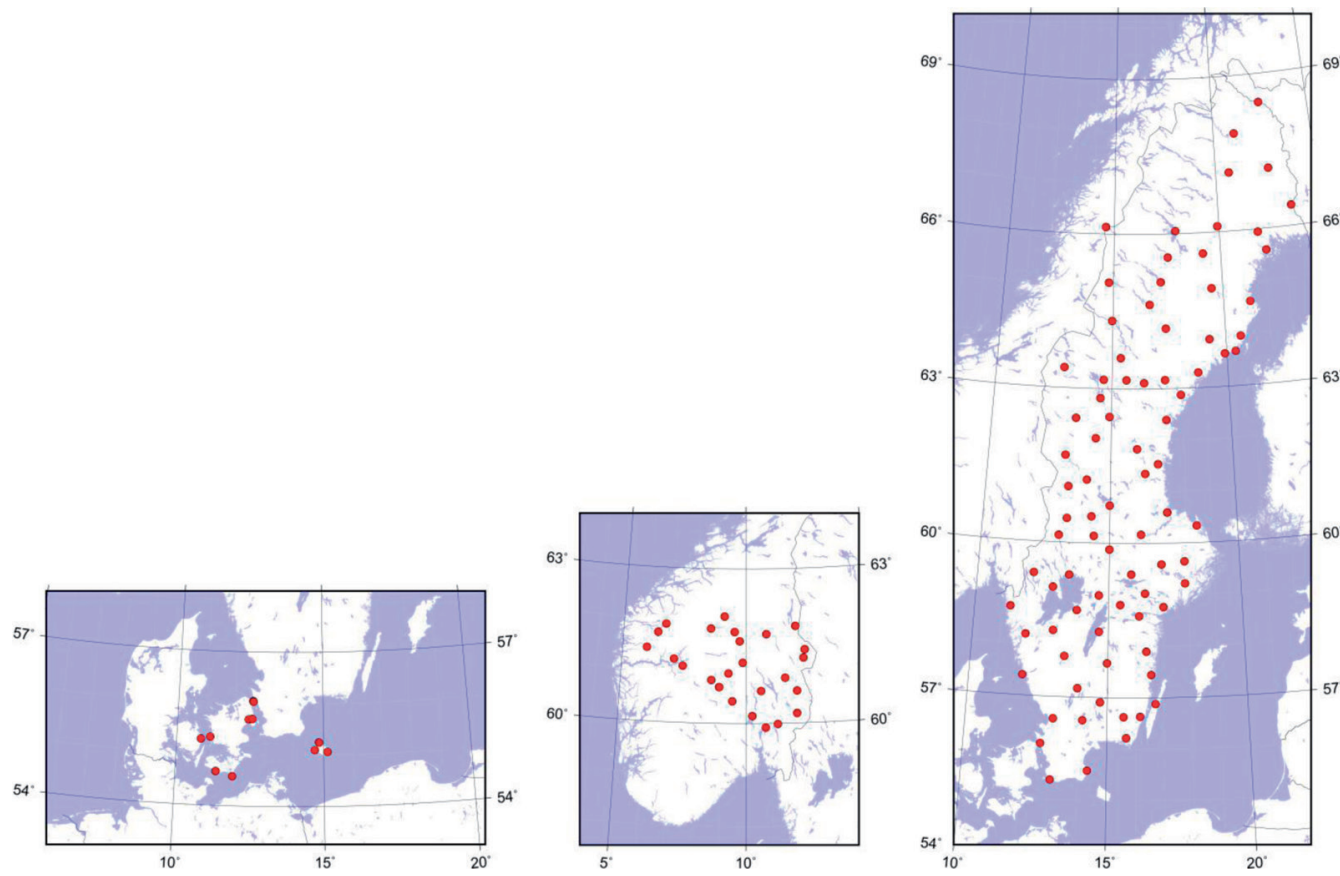

Fig. 6. Stations of gravity control networks of Denmark, Norway, and Sweden, and surveyed with the A10-020 in 2011-2013

\subsection{Absolute gravity surveys for geodynamic research}

Three field campaigns. in Pieniny Klippen Belt, in Sudeten Mts., and at Ksiaz Underground Geodynamic Laboratory have been conducted in 2011 for geodynamic purposes using the FG5-230 ballistic gravimeter (Krynski and Rogowski, 2012).

\subsection{Metrological aspects in gravimetry}

To maintain gravity control, in particular to ensure its standard in terms of gravity level and gravity unit, the free-fall gravimeters employed should regularly participate in the international absolute gravimeter comparison campaigns, and the relative gravimeters used should be respectively calibrated. Regular calibration of laser and frequency standard of free-fall gravimeters is also required. The A10-020 ballistic gravimeter of IGiK 
participated in $8^{\text {th }}$ International Comparison of Absolute Gravimeters ICAG 2009 in Paris in 2009 (Fig. 7) (Jiang et al., 2012) as well as in $9^{\text {th }}$ International Comparison of Absolute Gravimeters ICAG 2013 in Walferdange in 2013 (Krynski and Dykowski, 2014a).

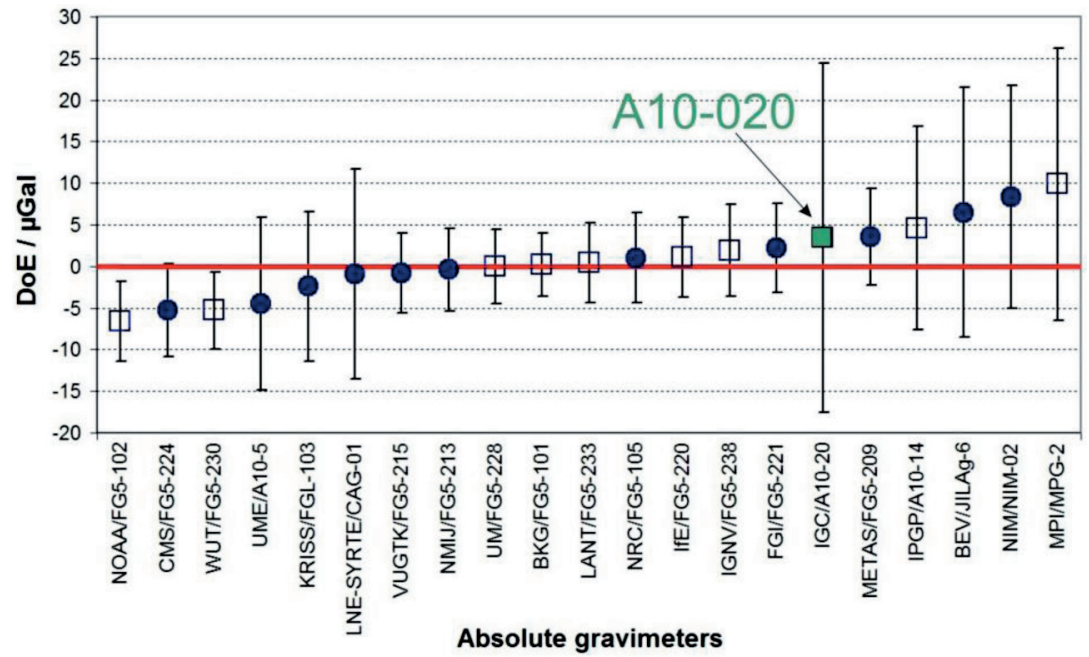

Fig. 7. Results of ICAG 2009 in Paris

Both Polish absolute gravimeters, i.e. FG5-230 of WUT and A10-020 of IGiK took part in the European calibration campaign ECAG 2011 in Walferdange, Luxemburg (Francis et al., 2013). The final results of the European Comparison Campaign of Absolute Gravimeters ECAG 2011 in Walferdange in Luxemburg proved high quality performance of the A10-020 gravimeter (Fig. 8) (Francis et al., 2012).

The effects of laser and clock stability and meteorological conditions on gravity surveyed with the A10-020 free-fall gravimeter were investigated. First results were obtained from the analysis of time series of regular, monthly measurements conducted with the A10-020 at the Borowa Gora Geodetic-Geophysical Observatory for over two years at two laboratory test sites and one field station. The analysis has been performed in terms of internal consistency and compliance with the previous gravity measurements performed with a few other absolute gravimeters (mainly FG5). The results of a number of calibrations of both, the rubidium oscillator and the polarization-stabilized laser interferometer of the A10-020 were considered in the analysis (Sekowski et al., 2012). Also accuracy and reliability of the A10-020 absolute gravimeter were estimated using time series of gravity determinations on the stations of the test network in Borowa Gora Geodetic-Geophysical Observatory (Krynski et al., 2014b).

Next, stability of metrological parameters and performance of the A10-020 free-fall gravimeter were investigated. It has been shown that calibrations of those parameters is a necessity to obtain proper gravity values with the A10 gravimeter (Dykowski et al., $2012 \mathrm{~b}$ ). The research on metrological aspects of gravity determinations with the A10020 gravimeter was particularly extensive during the establishment of a new gravity 


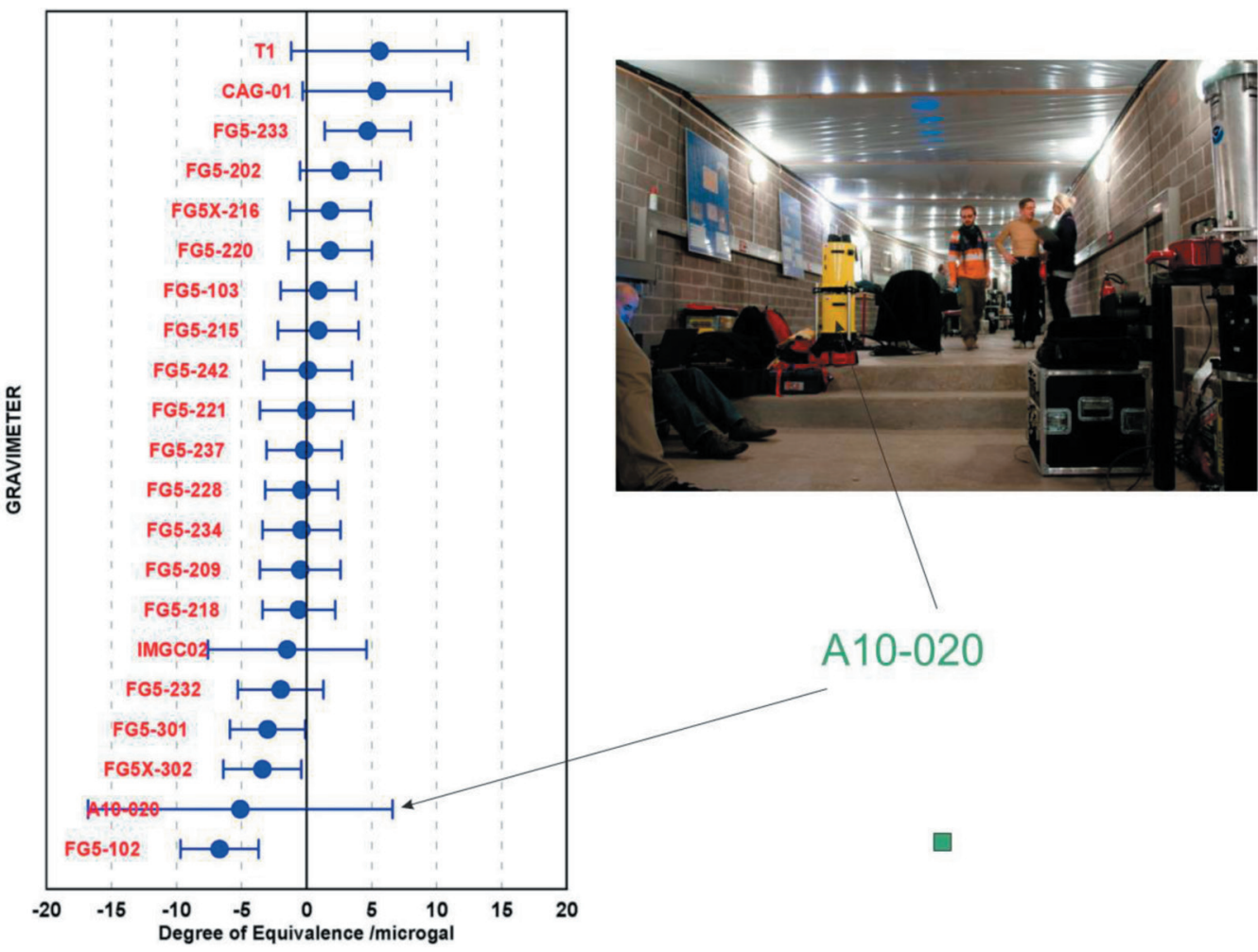

Fig. 8. Results of ECAG 2011 in Walferdange

control in Poland in 2012-2014 (Krynski et al., 2013; Krynski and Dykowski, 2013, 2014b). Long-term stability of the laser lock frequencies and clock frequency are shown in Figures 9 and 10, respectively (Dykowski et al., 2013a).

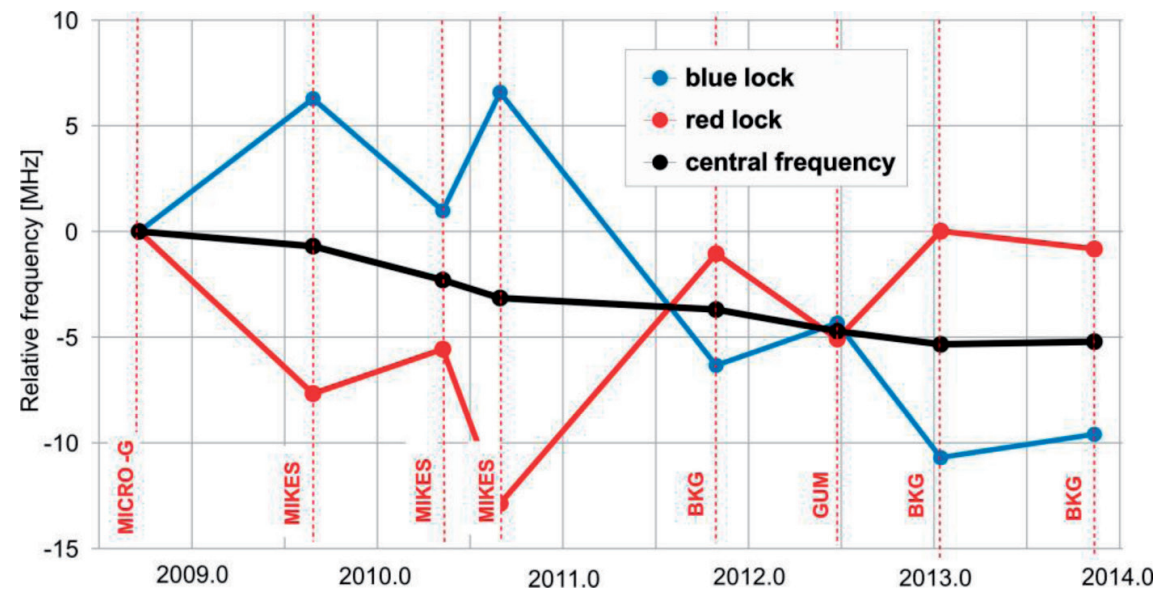

Fig. 9. Long-term stability of the laser lock frequencies of the A10-020 


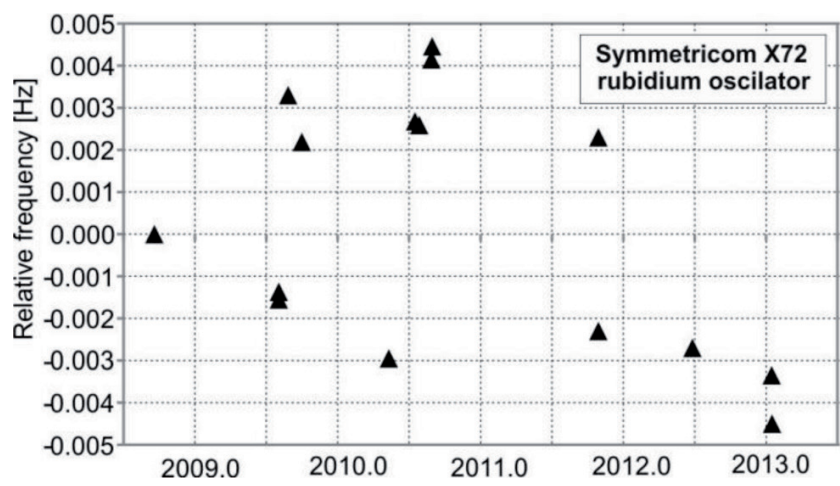

Fig. 10. Long-term stability of the clock frequency of the A10-020

The comprehensive study on the estimation of total uncertainty budget for the A10020 gravimeter was conducted. As the A10 gravimeter is used in both laboratory and field conditions two uncertainty estimates were considered. In addition, the sensitivity of the A10 gravimeter with respect to local hydrology has been discussed. The total uncertainty evaluations improved from the $10.8 \mu \mathrm{Gal}$ to $5.5 \mu \mathrm{Gal}$. The most significant change in the uncertainty estimates was observed in the system uncertainty. On one hand the estimates for the laser and clock uncertainties were larger than the manufacturer suggested. Yet, on the other hand the most dominant component of $10 \mu \mathrm{Gal}$ (system model uncertainty) has been replaced with the long term standard deviation of results at Borowa Gora Observatory. Values of $3.5 \mu \mathrm{Gal}$ (lab conditions) and $4.8 \mu \mathrm{Gal}$ (field conditions) had a profound influence on the total uncertainty estimate (Dykowski et al., 2013a).

The research on the use of the A10 gravimeter for calibration of spring gravimeters was conducted at IGiK. First results of the calibration with the use of the A10-020 provided scale factors with an accuracy close to $1 \%$ which is sufficient for the use of spring gravimeters for vertical gravity gradient determination (Dykowski 2012b).

\subsection{Environmental effects in absolute gravity determination}

All disturbing environmental and instrumental effects must be removed from absolute gravity measurements to make them useful for geodynamics research. Those, that can easily be modelled, e.g. tide, polar motion, ocean tidal loading, are routinely removed when processing measurements. Significant gravity variation is associated with changes of ground water on global scale. This effect was investigated for Lower Silesia region. Seasonal gravity changes can reach up to $2 \mu \mathrm{Gal}$ peak-to-peak amplitude. Using absolute gravity data acquired with the FG5-230 gravimeter it has been shown that neglecting this effect can cause serious misinterpretation in terms of secular gravity changes. This is specifically emphasized when only sparse data of a few year time span are used (Rajner et al., 2012). 


\section{Maintenance of gravimetric calibration baselines in Poland}

Two modernised gravimetric calibration baselines - the Central and the Western one are fully based on absolute gravity stations that are up to $100 \mathrm{~km}$ apart from each other; gravity differences between the stations range from 40 to $120 \mathrm{mGal}$. Also two vertical gravimetric calibration baselines in Tatra Mountains and in Sudeten Mountains (Krynski, 2011) are regularly maintained. The spans of the Central Gravimetric Calibration Baseline are regularly, at least once a year, surveyed with a set of LaCoste\&Romberg spring gravimeters of IGiK. At the end of 2014, new gravity measurements were performed with the FG5-230 of WUT at the all stations of the Central Gravimetric Calibration Baseline, Vertical Gravimetric Calibration Baseline in Tatra Mountains and some stations of the Western Gravimetric Calibration Baseline.

\section{Investigations of non-tidal gravity changes}

\subsection{Absolute gravity surveys in gravimetric laboratories}

\section{Absolute gravity surveys in Borowa Gora}

Since September 2008 absolute gravity measurements were conducted on monthly basis with the A10-020 gravimeter on the test network (two laboratory stations and one field station) of the Borowa Gora Geodetic-Geophysical Observatory of the Institute of Geodesy and Cartography (IGiK). The results obtained are regularly presented in annual National Reports of Poland to EUREF (Krynski and Rogowski, 2011, 2012, 2013, 2014) as well as in other publications (e.g. Krynski, 2011; Dykowski et al., 2013b). The statistics of the performed measurements at the laboratory stations A-BG and BG-G2 as well as for field station 156 of the test network are given in Table 7.

Table 7. Statistics of repeated absolute gravity determinations with the A10-020 on the stations of the local test gravity network in the Borowa Gora Geodetic-Geophysical Observatory [ $\mu \mathrm{Gal}]$

\begin{tabular}{|c|c|c|c|}
\hline Statistics & A-BG & BG-G2 & 156 \\
\hline Std dev. & 4.3 & 5.9 & 5.8 \\
\hline Max-Min & 15.2 & 24.0 & 29.8 \\
\hline
\end{tabular}

A series of gravity determined at the laboratory station A-BG of the test network is shown in Figure 11.

The A10-020 proved to be a reliable instrument also in terms of difficult weather conditions. Good agreement of the measurements taken with the A10-020 in Borowa Gora with the GLDAS/Noah corrections for hydrological conditions (for monthly solutions) was observed (Krynski and Dykowski, 2014a). 


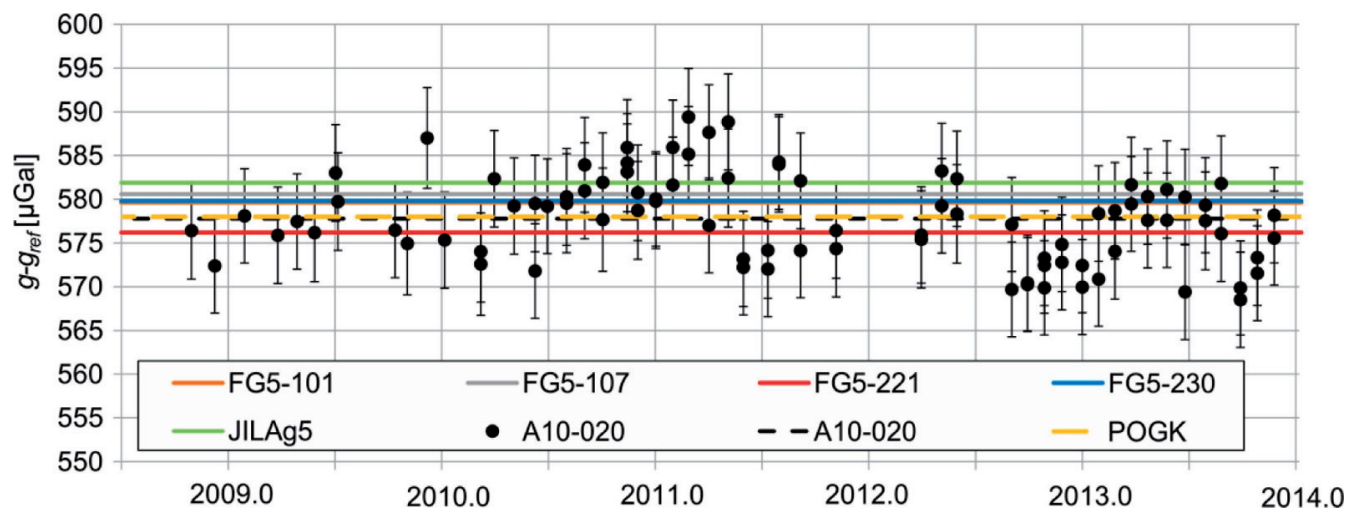

Fig. 11. Results of absolute gravity measurements with A10-020 at Borowa Gora

\section{Absolute gravity surveys in Jozefoslaw}

Absolute gravity measurements were carried out since 2005 on regular basis with the use of FG5-230 gravimeter in the Astrogeodetic Observatory in Jozefoslaw of the Warsaw University of Technology (WUT) (Fig. 12) (Krynski and Rogowski, 2011, 2012, 2013, 2014).

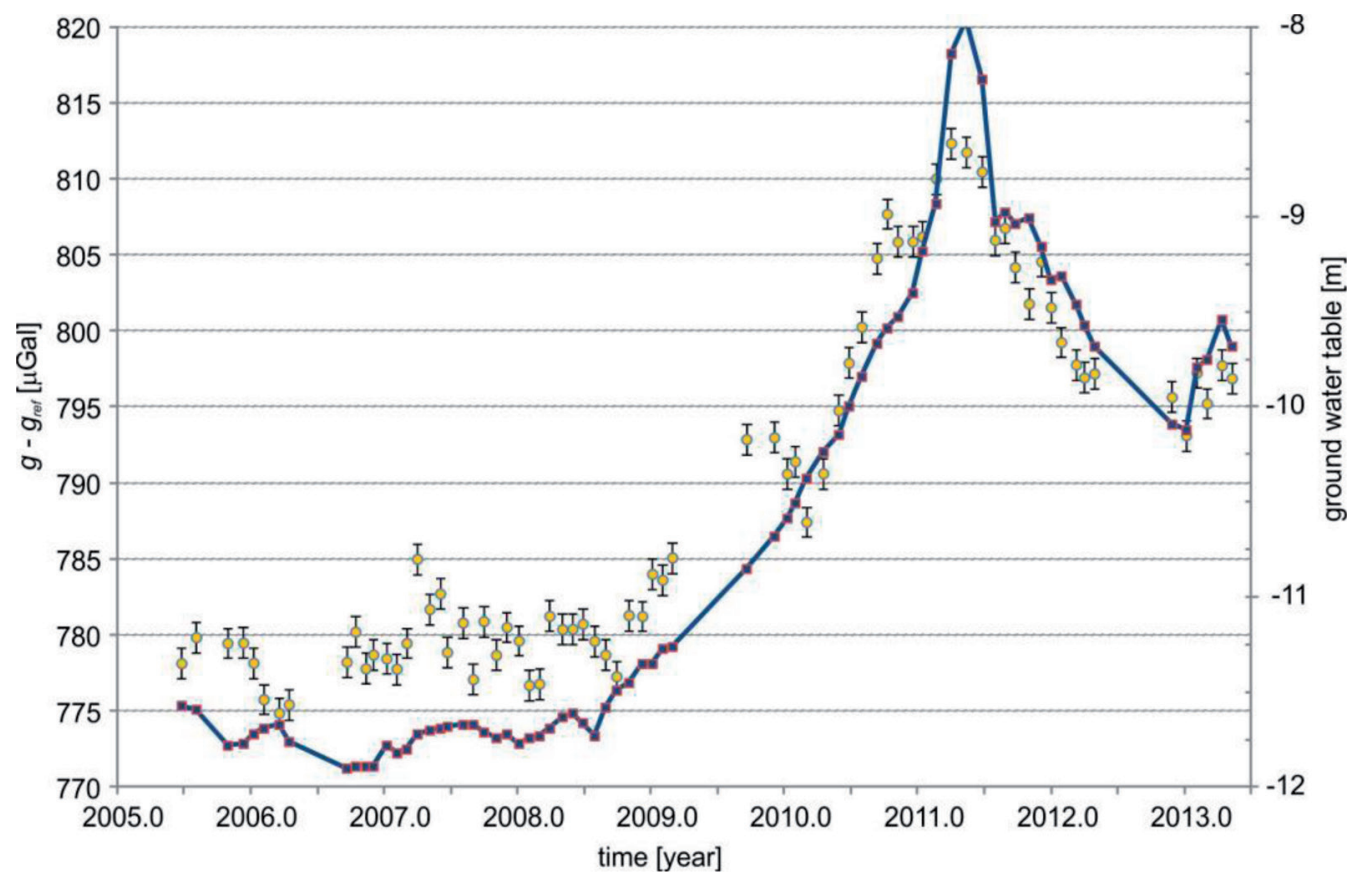

Fig. 12. Results of absolute gravity measurements with FG5-230 at Jozefoslaw (100 cm height) vs. ground water table 
The results of more than 3 years of absolute gravity survey in the Astrogeodetic Observatory in Jozefoslaw together with continuous records from the spring gravimeter were analysed (Barlik et al., 2011a), in particular in terms of environmental influence on gravity measurements (Fig. 13). The impact of atmosphere and hydrosphere on global and local scale was investigated.

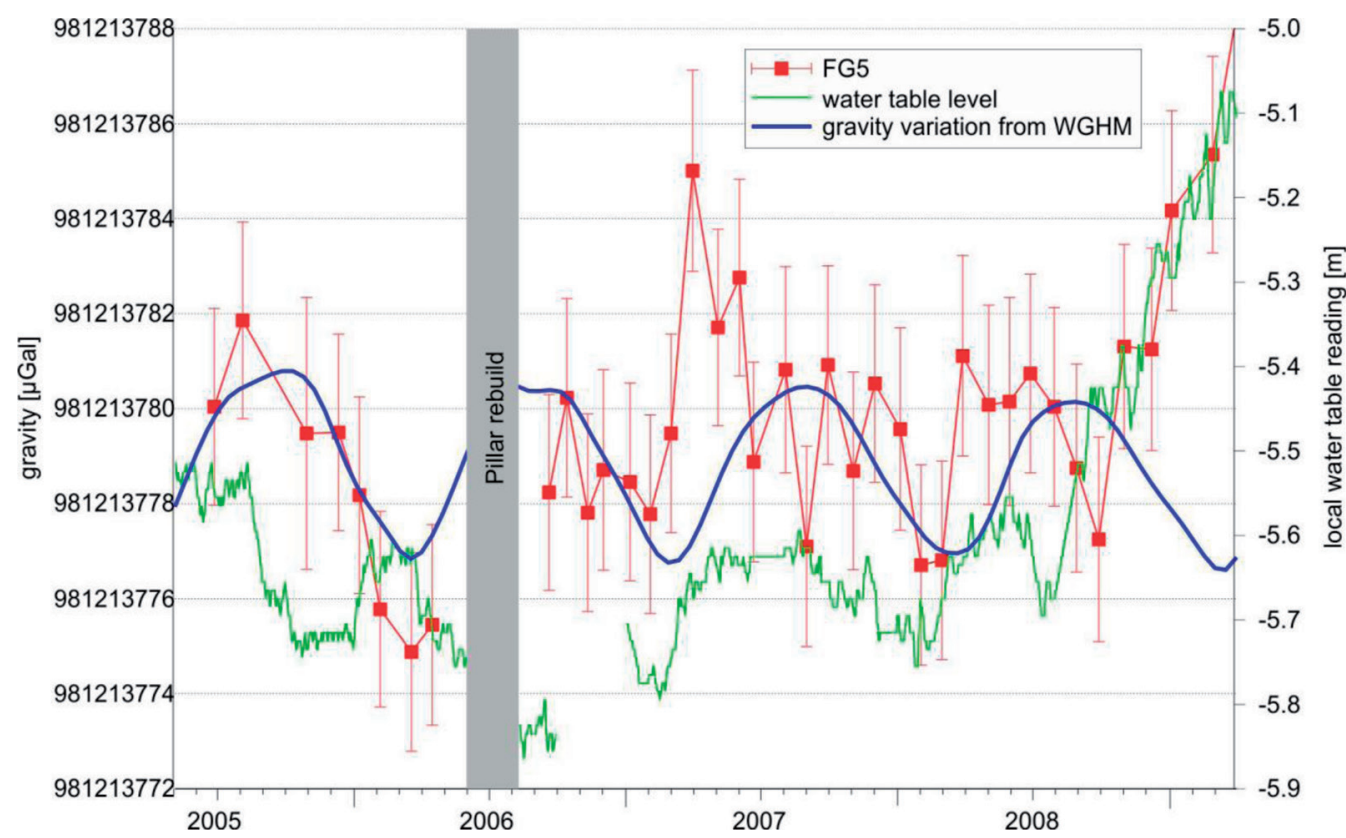

Fig. 13. Gravity measurements with the FG5-230 compared to gravity change due to continental water storage and local water table level variation

\section{Absolute gravity surveys in Ksiaz}

Absolute gravity was determined in the Geodynamic Laboratory (LG) of the Space Research Centre of the Polish Academy of Science in Ksiaz with the FG5-221 of the Finnish Geodetic Institute in April 2007 and then with FG5-230 of WUT twice in 2007 (June and November), once in April 2008 and once in June 2011. The results obtained indicated the existence of small variations of gravity at the level of $1 \mu \mathrm{Gal}$ with maxima in spring, and minima in the autumn. Very small amplitude of observed gravity variations in LG suggests that the observed gravity variations are caused only by global hydrology changes that exhibit maxima and minima in spring, and autumn, respectively, and annual amplitude of $1.5 \mu \mathrm{Gal}$. This proves high degree of ,independence" of gravimetric measurements in LG from local environmental factors such as ground water level variations, ground humidity, impact of snow cover, etc. Relative gravity measurements performed with LaCoste\&Romberg G-648 gravimeter simultaneously with absolute gravity measurements are used to improve local tidal model in Ksiaz (Kaczorowski et al., 2012). 


\subsection{Variations of the gravity record from $S G$ data}

Application of wavelet decomposition using the regular orthogonal symmetric Meyer wavelet to processing superconducting gravimeter (SG) data from Wettzell and Bad Homburg participating in the Global Geodynamics Project (GGP) was investigated. The wavelet transform enables the investigation of the temporal changes of the oscillation amplitudes or the decomposition of the time series for the analysis of the required frequencies. Data from an earthquake period recorded at various locations and a quiet period with no seismic disturbances were analysed. The decomposition was followed by the Fast Fourier Transform for signal frequency components and then by correlation analyses of corresponding frequency components for all sensor combinations, for the quiet and the earthquake periods separately. Low frequency components as well as combinations between two sensors at the same site for the quiet days characterise by high correlation coefficients. For the time of the earthquake, the Wettzell site data proved strong correlation for all frequency components, while the Bad Homburg site data showed an unexpected decrease of correlation for the majority of frequency components. It has been proven that wavelet decomposition is a suitable method for data interpolation, especially from the time of earthquakes. Moreover, it is a very useful tool for filtering the data and removing noise (Bogusz et al., 2013).

\section{Summary and conclusions}

Research on gravity field modelling in research centres in Poland concentrated on the evaluation of GOCE-derived global geopotential models, geoid modelling and temporal variations of the gravity field.

High quality terrestrial data from Poland allowed for reliable evaluation of GOCEbased GGMs. Special role of uniformly distributed absolute gravity data in such evaluation was indicated. The results obtained showed the usefulness of GOCE-based GGMs for developing reference surface for heights, in particular in the regions with insufficient terrestrial data. Analysis of geoid models developed for the area of Poland (accuracy at the level of $2 \mathrm{~cm}$ ) and the area of Sudan with the use of GOCE-based GGMs indicated that those global geopotential models can be recommended as best reference surface for GNSS heighting in Sudan. Some practical conclusions were drawn when studying the application of the method of local quasigeoid modelling based on gravity data inversion. GRACE data was found useful for determining temporal variations of the gravity field in Europe. Equivalent water heights variation obtained using GRACE models are correlated with those from hydrological models. Geoid height variations have been estimated for subareas of Europe. It also was shown that they reliably be modelled by a seasonal term and a trend in the form of the $2^{\text {nd }}$ order polynomial. It was highlighted that the concept of static geoid as a reference surface in precise heighting, with the use of contemporary global positioning techniques becomes outdated. There is thus a growing need for kinematic models of gravimetric geoid. 
An extensive study of the A10-020 ballistic gravimeter showed its usefulness for the maintenance and modernization of gravity control. Absolute gravity surveys with the A10-020 gravimeter were successfully conducted on the stations of gravity control in Denmark, Norway, Finland, Poland and Sweden. Also accuracy and reliability as well as total uncertainty of the A10-020 in both laboratory and field conditions were estimated using time series of gravity determinations in Borowa Gora GeodeticGeophysical Observatory which is essential for the evaluation of the quality of gravity control. Absolute gravity measurements carried out on regular basis with the use of FG5-230 gravimeter in the Astrogeodetic Observatory in Jozefoslaw were analysed in terms of environmental influence on gravity measurements. Non-tidal gravity changes were also investigated with the use of repeatable absolute gravity measurements with the FG5-230 in Pieniny Klippen Belt, in Sudeten Mts. and at Geodynamic Laboratory in Ksiaz.

\section{Acknowledgements}

The review paper was elaborated in the framework of the statutory project "Problems of geodesy and geodynamics" of the Institute of Geodesy and Cartography (IGiK), Warsaw, financially supported by the Polish Ministry of Science and Higher Education. Valuable help was provided by Marcin Barlik, Monika Birylo, Przemyslaw Dykowski, Adam Lyszkowicz, Marcin Rajner, Marek Trojanowicz.

\section{References}

Barlik, M., Rajner, M. and Olszak, T. (2011a). Analysis of Measurements Collected in Gravity Laboratory in Józefosław Observatory during 2007-2010. Proceedings of the Symposium on Terrestrial Gravimetry. Static and Mobile Measurements (TG-SMM2010), Sankt Petersburg, 22-25 June 2010, (ed) V. Peshekhonov, pp. 116-120.

Barlik, M., Krynski, J., Olszak, T., Cisak, J., Pachuta, A., Dykowski, P., Walo, J., Zak, L., Szpunar, R., Jedrzejewska, A., Marganski, S., Prochniewicz, D. and Drozdz, M. (2011b). Project and the control survey of gravity control in Poland - stage I (in Polish), Technical report for the Head Office of Geodesy and Cartography (36 pp).

Birylo, M. and Nastula, J. (2013a). Local Equivalent Water Thickness determination as a source of data for flood phenomenon observation. Papers on Global Change, Vol. 19, 2012, 42-53, DOI 10.2478/ v10190-012-0003-8

Biryło, M. and Nastula, J. (2013b). GRACE Signal Filtering as a Means of Determining Equivalent Water Thickness in Poland. Papers on Global Change, Vol. 19, 2012, 33-42, DOI 10.2478/v10190-012-0009

Bogusz, J., Klos, A. and Kosek, W. (2013). Wavelet decomposition in the earth's gravity field investigation. Acta Geodynamica et Geomaterialia, Vol. 10, No 1(169), 47-59, DOI 10.13168/AGG.2013.0004

Dykowski, P. (2012a). Vertical gravity gradient determination for the needs of contemporary absolute gravity measurements - first results. Reports on Geodesy, Vol. 92, No 1, 23-36.

Dykowski, P. (2012b). Calibration of Relative Spring Gravimeters with the Use of the A10 Absolute Gravimeter, Symposium Gravity. Geoid and Height Systems GGHS2012, Venice, Italy, 9-12 October 2012 . 
Dykowski, P., Sekowski, M. and Krynski, J. (2012a). Testing the suitability of the A10-020 absolute gravimeter for the establishment of new gravity control in Poland. IAG Symposia Vol. 140, (ed.) P. Willis, Symposium Gravity, Geoid and Height Systems GGHS2012, Venice, Italy, 9-12 October 2012.

Dykowski, P., Krynski, J., and Sekowski, M. (2012b). Stability of metrological parameters and performance of the A10 free-fall gravimeter. Geophysical Research Abstracts Vol. 14, EGU2012-4449, EGU General Assembly 2012, 22-27 April, Vienna, Austria.

Dykowski, P., Krynski, J. and Sekowski, M. (2013a). Approach to the A10 gravimeter total uncertainty budget estimation. IAG Scientific Assembly 2013, 1-6 September, Potsdam, Germany, IAG Symposia Vol. 143, (ed.) P. Willis, IAG Scientific Assembly 2013, Potsdam, Germany, 1-6 September 2013.

Dykowski P., Krynski J., Sekowski M., (2013b). Gravimetric investigations at Borowa Gora Geodetic Geophysical Observatory. Geophysical Research Abstracts Vol. 15, EGU2013-8315, EGU General Assembly 2013, 7-12 April, Vienna, Austria.

Francis, O., Klein, G., Baumann, H., Dando, N., Tracey, R., Ullrich, C., Castelein, S., Hua, H., Kang, W., Chongyang, S., Songbo, X., Hongbo, T., Zhengyuan, L., Pálinkás, V., Kostelecký, J., Mäkinen, J., Näränen J., Merlet, S., Farah, T., Guerlin, C., Pereira Dos Santos, F., Le Moigne, N., Champollion, C., Deville, S., Timmen, L., Falk, R., Wilmes, H., Iacovone, D., Baccaro, F., Germak, A., Biolcati, E., Krynski, J., Sekowski, M., Olszak, T., Pachuta, A., Agren, J., Engfeldt, A., Reudink, R., Inacio, P., McLaughlin, D., Shannon, G., Eckl, M., Wilkins, T., van Westrum, D. and Billson, R. (2012). Final report of the regional key comparison EURAMET.M.G-K1. European Comparison of Absolute Gravimeters ECAG-2011. Metrologia, Vol. 49, Issue 1A, 07-014, doi.10.1088/0026-1394/49/1A/07014.

Francis, O., Baumann, H., Volarik, T., Rothleitner, Ch., Klein, G., Seil, M., Dando, N., Tracey, R., Ullrich, C., Castelein, S., Hua, H., Kang, W., Chongyang, S., Songbo, X., Hongbo, T., Zhengyuan, L., Pálinkás, V., Kostelecký, J., Mäkinen, J., Näränen, J., Merlet, S., Farah, T., Guerlin, C., Pereira Dos Santos, F., Le Moigne N., Champollion, C., Deville, S., Timmen, L., Falk, R., Wilmes, H., Iacovone, D., Baccaro, F., Germak, A., Biolcati E., Krynski J., Sekowski M., Olszak T., Pachuta, A., Agren, J., Engfeldt, A., Reudink, R., Inacio, P., McLaughlin, D., Shannon, G., Eckl, M., Wilkins, T., van Westrum, D. and Billson, R. (2013). The European Comparison of Absolute Gravimeters 2011 (ECAG2011) in Walferdange, Luxembourg. results and recommendations. Metrologia, Vol. 50,. 257-268, doi.10.1088/0026-1394/50/3/257.

Godah, W. and Krynski, J. (2011). Validation of GOCE geopotential models over Poland using the EGM2008 and GPS/levelling data. Geoinformation Issues, Vol. 3, No 1, 5-17.

Godah, W. and Krynski, J. (2012). Accuracy assessment of the $3^{\text {rd }}$ release of GOCE GGMs over the area of Poland using EGM2008 and GPS/levelling, GOCE Solid Earth Workshop, 16-17 October 2012, Enschede, The Netherlands.

Godah, W. and Krynski, J. (2013a). Evaluation of recent GOCE global geopotential models over the area of Poland. Acta Geodynamica et Geomaterialia, Vol. 10, No 3(171), 257-268, doi.10.1088/0026$1394 / 50 / 3 / 257$

Godah, W. and Krynski, J. (2013b). Accuracy assessment of the $3^{\text {rd }}$ release of GOCE GGMs over the area of Sudan. Int. J. of Applied Earth Observation and Geoinformation, JAG797, doi. 10.1016/j. jag.2013.11.003.

Godah, W. and Krynski, J. (2014). A new gravimetric geoid model for the area of Sudan using the least squares collocation and a GOCE-based GGM, The $3^{\text {rd }}$ International Gravity Field Service (IGFS) General Assembly, Shanghai, China, 30 June - 6 July 2014; IAG Symposia Vol. 145, (ed.) P. Willis.

Godah, W., Szelachowska, M. and Krynski, J. (2014a). Accuracy assessment of GOCE-based geopotential models and their use for modelling the gravimetric quasigeoid - A case study for Poland, Geodesy and Cartography, Vol. 63, No 1, 3-24, DOI: 10.2478/geocart-2014-0001

Godah, W., Krynski, J. and Szelachowska, M., (2014b). On the contribution of GOCE mission to modelling the gravimetric geoid. A case study - a sub-region of East Africa and Central Europe. The $3^{\text {rd }}$ International Gravity Field Service (IGFS) General Assembly, Shanghai, China, 30 June - 6 July 2014. 
Godah, W., Krynski, J., Szelachowska, M., Dykowski, P. and Sekowski, M. (2014c). The use of absolute gravity data for validation of GOCE-based GGMs - A case study of Central Europe. $5^{\text {th }}$ GOCE User Workshop, 25-28 November 2014, Paris, France.

Jiang Z., Pálinkáš V., Arias F.E., Liard J., Merlet S., Wilmes H., Vitushkin L., Robertsson L., Tisserand L., Pereira Dos Santos F., Bodart Q., Falk R., Baumann H., Mizushima S., Mäkinen J., Bilker-Koivula M., Lee C., Choi I.M., Karaboce B., Ji W., Wu Q., Ruess D., Ullrich C., Kostelecký J., Schmerge D., Eckl M., Timmen L., Le Moigne N., Bayer R., Olszak T., Ågren J., Del Negro C., Greco F., Diament M., Deroussi S., Bonvalot S., Krynski J., Sekowski M., Hu H., Wang L.J., Svitlov S., Germak A., Francis O., Becker M., Inglis D., Robinson I., (2012). The $8^{\text {th }}$ International Comparison of Absolute Gravimeters 2009. the first Key Comparison (CCM.G-K1) in the field of absolute gravimetry. Metrologia, Vol. 49, No 6, 666-684, doi.10.1088/0026-1394/49/6/666.

Kaczorowski, M., Olszak, T., Walo, J. and Barlik, M. (2012). Research on absolute gravity variations in geodynamic laboratory in Ksiaz in the period of 2007 - 2011. Artificial Satellites, Journal of Planetary Geodesy, Vol. 47, No 4, 169-176.

Kloch-Glowka, G., Krynski, J. and Szelachowska, M. (2012). Time variations of the gravity field over Europe obtained from GRACE data. Reports on Geodesy, Vol. 92, No 1, 175-190.

Krynski, J. (2007). Precise modelling of quasigeoid in Poland - wyniki results and accuracy estimate (in Polish). Monographic series of the Institute of Geodesy and Cartography, Nr 13, Warsaw 2007 (266 pp).

Krynski, J. (ed.) (2011). Polish National Report on Geodesy 2007-2010, XXV General Assembly of the International Union of Geodesy and Geophysics, Melbourne, Australia, 28 June - 7 July 2011 (134 pp).

Krynski, J. (2012a). On the new International Gravity Reference System. Workshop of JWG 2.1 Techn. and Metrology in Abs. Grav. and JWG 2.2 Abs. Grav and Abs. Grav. Ref. System, Vienna, Austria, $14-15$ Febr.

Krynski, J. (2012b). Gravimetry for geodesy and geodynamics - brief historical review. Reports on Geodesy, Vol. 92, No 1, 69-86.

Krynski, J. and Dykowski, P. (2013). Establishment of new gravity control in Poland - current status. IAG Scientific Assembly 2013, 1-6 September, Potsdam, Germany.

Krynski, J. and Dykowski, P. (2014a). The use of the A10-020 absolute gravimeter for the modernization of gravity control in Poland. The $3^{\text {rd }}$ International Gravity Field Service (IGFS) General Assembly, Shanghai, China, 30 June - 6 July 2014.

Krynski, J. and Dykowski, P. (2014b). Establishment of new gravity control in Poland - first results. Geophysical Research Abstracts Vol. 16, EGU2014-14048, EGU General Assembly 2014, 27 April 2 May, Vienna, Austria.

Krynski, J. and Rogowski, J.B. (2011). National Report of Poland to EUREF 2011, Symposium of the IAG Subcommission for Europe (EUREF) held in Chisinau, Moldova, 25-28 June 2011, http.//www.eurefiag.net/symposia/2011Chisinau/07-22-p-Poland.pdf.

Krynski, J. and Rogowski, J.B. (2012). National Report of Poland to EUREF 2012.Symposium of the IAG Subcommission for Europe (EUREF) held in Paris, France, 6-8 June 2012, http.//www.euref-iag.net/ symposia/2012Paris/06-22-p-Poland.pdf.

Krynski, J. and Rogowski, J.B. (2013). National Report of Poland to EUREF 2013. Symposium of the IAG Subcommission for Europe (EUREF) held in Budapest, Hungary, 29-31 May 2013, http.//www.eurefiag.net/symposia/2013Budapest/06-22-p-Poland.pdf.

Krynski, J. and Rogowski, J.B. (2014). National Report of Poland to EUREF 2014. Symposium of the IAG Subcommission for Europe (EUREF) held in Vilnius, Lithuania, 4-6 June 2014, http.//www.euref-iag. net/symposia/2014Vilnius/05-20-p-Poland.pdf.

Krynski, J., Kloch-Glowka, G. and Szelachowska, M. (2012). On variability of geoid in Europe. Symposium of the IAG Subcommission for Europe (EUREF) held in Paris, France, 6-8 June 2012, http.//www. euref-iag.net/symposia/2012Paris/05-01-Krynski.pdf

Krynski, J., Cisak, J., Sekowski, M., Dykowski, P., Godah, W., Jedrzejewska, A. and Zak, L. (2013). Survey of the base stations of the gravity control in Poland with data processing (Second stage) (in Polish). Report for the Head Office of Geodesy and Cartography, December 2013, Warsaw (32 pp). 
Krynski, J., Kloch-Glowka, G. and Szelachowska, M. (2014a). Analysis of time variations of the gravity field over Europe obtained from GRACE data in terms of geoid height and mass variation. IAG Symposia Vol. 139, C. Rizos and P. Willis (eds.), Earth on the Edge. Science for a Sustainable Planet, XXV IUGG General Assembly, Melbourne, Australia, 28 June - 7 July 2011, pp. 365-370, DOI 10.1007/978-3-642-37222-3_48.

Krynski, J., Dykowski, P., Sekowski, M. and Mäkinen, J. (2014b). On the estimate of accuracy and reliability of the A10 absolute gravimeter. IAG Symposia Vol. 139, C. Rizos and P. Willis (eds.), Earth on the Edge. Science for a Sustainable Planet, XXV IUGG General Assembly, Melbourne, Australia, 28 June - 7 July 2011, pp. 297-302, DOI 10.1007/978-3-642-37222-3_39.

Lyszkowicz, A. (2012). Geoid in the area of Poland in author's investigations. Technical Sciences, No 15(1), 49-64.

Lyszkowicz, A., Birylo, M. and Becek, K. (2014). A new geoid for Brunei Darussalam by the collocation method. Geodesy and Cartography, Vol. 63, No 2, 2014, 183-198. DOI: 10.2478/geocart-2014-0013

Mäkinen, J., Sekowski, M., Krynski, J., Näränen, J., Raja-Halli., Ruotsalainen, H. and Virtanen, H. (2011). Gravity change in Finland 1962-2010 from the comparison of legacy relative measurements with new measurements made with the outdoor absolute gravimeter A10. Geoph. Res. Abstr., Vol. 13, EGU2011-12587.

Pettersen, B.R., Sprlak, M., Lysaker, D.I., Omang, O.C.D., Sekowski, M. and Dykowski P. (2012a). Validation of GOCE by absolute and relative gravimetry. Geophysical Research Abstracts Vol. 14, EGU2012-7593, EGU General Assembly 2012, 22-27 April, Vienna, Austria.

Pettersen, B.R., Sprlak, M., Omang, O.C.D., Lysaker, D.I., Sekowsk,i M. and Dykowski, P. (2012b). Comparison of GOCE gravity field models to test fields in Norway. IAG Symposia Vol. 140, (ed.) P. Willis, Symposium Gravity, Geoid and Height Systems GGHS2012, Venice, Italy, 9-12 October 2012 (in print).

Rajner, M., Olszak, T., Rogowski, J. and Walo, J. (2012). The influence of continental water storage on gravity rates estimates. case study using absolute gravity measurements from area of Lower Silesia, Poland. Acta Geodynamica et Geomaterialia, Vol. 9, No 4(168), 449-455.

Sekowski, M., Krynski, J., Dykowski, P. and Mäkinen, J. (2012). Effect of laser and clock stability and meteorological conditions on gravity surveyed with the A10 free-fall gravimeter - first results, Reports on Geodesy, Vol. 92, No 1, 47-59.

Trojanowicz, M. (2012a). Local modelling of quasigeoid heights with the use of the gravity inverse method - case study for the area of Poland. Acta Geodynamica et Geomaterialia, Vol. 9, No 1(165), 5-18. URL. http.//www.irsm.cas.cz/abstracts/AGG/01_12/1_Trojanowicz.pdf

Trojanowicz, M. (2012b). Local quasigeoid modelling using gravity data inversion technique - analysis of fixed coefficients of density model weighting matrix. Acta Geodynamica et Geomaterialia, Vol. 9, No 3(167), 269-281. URL. http.//www.irsm.cas.cz/abstracts/AGG/03_12/3.Trojanowicz.pdf 